Meta

Journal des tradlucteurs

Translators' Journal

\title{
The Kintsch and Van Dijk Model of Discourse Comprehension and Production Applied to the Interpretation Process
}

Jennifer Mackintosh

Volume 30, numéro 1, mars 1985

Interprétation de conférence

URI : https://id.erudit.org/iderudit/003530ar

DOI : https://doi.org/10.7202/003530ar

Aller au sommaire du numéro

Éditeur(s)

Les Presses de l'Université de Montréal

ISSN

0026-0452 (imprimé)

1492-1421 (numérique)

Découvrir la revue

Citer cet article

Mackintosh, J. (1985). The Kintsch and Van Dijk Model of Discourse

Comprehension and Production Applied to the Interpretation Process. Meta,

30(1), 37-43. https://doi.org/10.7202/003530ar 


\title{
THE KINTSCH AND VAN DIJK MODEL OF DISCOURSE COMPREHENSION AND PRODUCTION APPLIED TO THE INTERPRETATION PROCESS
}

\author{
JENNIFER MACKINTOSH
}

Over the past ten years conference interpretation has become an object of research and a small number of authors (see below) have proposed models which seek to characterise different aspects of the processes involved. In this brief review, an attempt will be made to identify the main features of existing CI models and to present an outline of the Kintsch \& Van Dijk model. Its applicability to CI will be illustrated by some examples taken from an experimental corpus of consecutive and simultaneous interpretation.

In 1976, D. Gerver published a comprehensive review of existing work, either on CI or relevant to it, in Translation ( $\mathbf{R}$. Brislin, ed.), which included a model based on an information processing approach to conference interpreting. However, although the model comprised the usual features of such a model with a short-term and long-term memory, and the identification of an initial phase during which the phonological input is processed and a subsequent phase during which the discourse segment thus processed is represented conceptually in memory, it does not address itself directly to the semantic processing of the message, i.e. to how the discourse is comprehended and the meaning thus established reproduced by the interpreter in the target language (TL). It is this feature : the identification of meaning and, to a lesser extent, the reproduction of that meaning, which is the object of the Seleskovitch-Lederer paradigm, on which research and teaching at the École supérieure des interprètes et traducteurs (ÉSIT) is based. This postulates a three-phase operation in which the first phase is verbal (incoming discourse), the second is non-verbal and the third is again verbal (the interpreter's reproduction of the message in the TL). During the non-verbal phase the verbal input becomes 'chunked' into units of meaning, which Lederer defines as follows :

l'énoncé plus la réaction cognitive qui s'exerce sur lui forme (...) l'ensemble que j'appelle unité de sens et qui est à mes yeux l'unité minimum de la parole en deçà de laquelle il n'y a pas encore de sens mais seulement des mots avec chacun leur signification propre. (M. Lederer $1976:$ ELA 24, p. 16.)

These units of meaning then fuse with prior knowledge (context-specific or world knowledge) and

basculent dans la mémoire cognitive en perdant toute forme verbale, l'unité de sens devient idée. (M. Lederer, art. cit.) 
As D. Seleskovitch stated in the Threlford Memorial Lecture to the Institute of Linguists in February 1977

(...) the translation process appears to be not a direct conversion of the linguistic meaning of the source language to the target language but a conversion from source language to sense, the intermediate link being non-verbal thought which, once consciously grasped, can then be expressed in any language regardless of the words used in the original language. (Seleskovitch 1977)

In la Traduction simultanée (1981), Lederer develops the above model, postulating the existence of an immediate memory, operating essentially on the phonological input (having a capacity of 7-8 words and a holding time of 2-3 secs, see op. cit., p. 276) and a short-term cognitive memory which is the basis of a semantic memory

dans laquelle les sèmes se trouvent dissociés de leur support formel. (Op. cit., p. 279.)

Although Lederer touches upon the processes whereby a message proceeds from one memory to the next (op. cit., p. 282), there are no systematic rules in the model which can account for this process, contrary to the Kintsch \& Van Dijk model which comprises mapping rules.

Moser (1978) presents a working interpretation model which is based on Massaro (1975). Moser describes the Massaro model as

... an attempt to describe the temporal flow of auditory information, beginning with the acoustic signal (...) that arrives at the ear of the listener and ending with some form of mental representation of the message in the mind of the listener. (Moser $1978: 353$ )

Moser takes this model and extends it to include the third phase, specific to CI, which is reproduction of the message in the TL. Massaro's model, like the Kintsch \& Van Dijk one was not developed with CI in mind. In this model, the phonological input is chunked into information segments (comparable to the unités de sens of the Seleskovitch-Lederer model), at which point the verbal characteristics are lots and processing is seen as an essentially semantic operation involving memory search of the conceptual base and the activation of conceptual relations. It also provides for different levels of memory and addresses the important question of how syntactic (languagedependent) and semantic (language-independent) information is organised and accessed. Moser refers to Schank (1972) and his suggestion that people have a common conceptual base which is independent of language and his premise that in order to translate, a person will invoke mapping rules for a given language and apply them to that base. Production, i.e. the third phase, is seen as a process in which concepts, organised around the verb, are combined and output gos forward according to the syntactic rules of the TL. None of the models referred to so far addresses the question of whether there is an additional processing requirement (and load) as a result of the interpreter having to operate two languages (i.e. two lexical stores, as well as two syntactic and stylistic systems) simultaneously.

Lambert (1983) has addressed this question in a study which used levels of recall and recognition among conference interpreters as an indication of processing depth. Out of the four conditions Listening, Consecutive Interpretation, Simultaneous Interpretation and Shadowing, recall was highest for the first and then decreased in the order shown. If we assume that the Listening task (the message being received in one language and then subsequently recalled in another) provides a measurement of a subject's recall capability, it could be argued that the lower scores for the three other conditions indicate the additional processing load represented by each. On this basis, the load is greater 
for Simultaneous than for Consecutive. That assumption is, however, weakened by the results for Shadowing - a task that requires little or no semantic processing. In a second set of experiments, to provide a control, subjects were required to work monolingually (thus excluding Simultaneous), from their A language into their $\mathrm{A}$ language. The recall scores for Listening and Consecutive were slightly (non-significantly) lower than for the two-language condition, suggesting that operating in two languages increases rather than diminishes depth of processing. However, in an experiment I conducted at the Polytechnic of Central London on relay in consecutive interpretation the level of message loss for the two-language condition was significantly higher than for the monolingual, control group.

\section{THE KINTSCH AND VAN DIJK MODEL}

The model was published in the Psychological Review (1978). In Macrostructures (1980) Van Dijk develops the 1978 model, particularly with regard to its theoretical underpinning and aspects such as the theory of action and speech acts without, however, changing the essential features of the model. This brief discussion will therefore be based as much on Van Dijk (1980) as on Kintsch and Van Dijk (1978). The model is a semantic processing model characterising comprehension and production and therefore covers the three phases identified above. It specifies three sets of operation

i) organisation of the text into a coherent whole

ii) condensing the full meaning of the text into its gist

iii) generation of a new text from the memory traces of the comprehension process and it posits the organisation of semantic structures on a number of levels, from microstructures to successive levels of macro-structures, each one being a condensation of any number greater than one of those below it. The model also comprises rules governing the passage from one level to the next. The model assumes that the

surface structure of a discourse is interpreted as a set of propositions. (Kintsch \& Van Dijk $1978: 365$ )

with some of the propositions present in the surface structure and others being inferred. Inferencing is done on the basis of prior knowledge, stored in long-term memory. According to the model, the propositions thus formed, called micropropositions, are processed by a working memory to establish coherence with the propositions already stored in short-term memory (i.e. the previous segment to have been processed). The short-term memory capacity is about five propositions and it acts as a buffer while the working memory searches for argument overlap between incoming propositions and those already in short-term memory. In the absence of overlap, the working memory then searches long-term memory. If argument overlap is established (directly or as a result of inferencing), the proposition in working memory enters short-term memory. The micropropositions thus accepted and stored constitue the microstructures of the model. Microstructures are processed into macrostructures by application of the macrorules :

1. Deletion : if a proposition is not necessary, directly or indirectly, to the interpretation of a subsequent proposition, it may be deleted.

2. Generalisation : a general proposition denoting an immediate superset may replace any sequence of propositions.

3. Construction : any sequence of propositions may be replaced by one denoting a global fact of which the micropropositions are normal constituents.

In production an inverse process operates whereby the deletion rule is replaced by an addition rule; generalisation by particularisation; construction by specification. These rules are applied to the macropropositions to reproduce the micropropositions which appear in discourse. 
In comprehension the macrorules account for the process whereby the local level of discourse becomes organised at a global macro-level. A first set of deletion and generalisation operations may produce a macroproposition which is then further generalised in a subsequent application of the rules. Similarly, application of the construction rule may simultaneously delete or generalise macropropositions contained in the subordinate level of the macrostructure. Macrorules are applied under the control of a schema which determines what belongs (i.e. what is relevant) to the text base, constituted by propositions organised into a structured coherent whole.

\section{APPLICABILITY TO CONFERENCE INTERPRETING}

It is generally agreed (inter alia Herbert 1952, Rozan 1956, Seleskovitch 1975, Ilg 1980, Willett 1974, Lambert 1983) that in consecutive interpretation, the interpreter notes down the essential features of the message and its structure

Notizenaufnahme beim Konsekutivdolmetschen heisst nicht, Wörter mitschreiben, sondern blitzschnell den Inhalt analysieren, den diese Wörter vermitteln, ihn zu assimilieren und ihn in der einfachsten Form - als Gedankstütze - auf dem Papier zu verankern. (Willett $1974: 100$ )

and, when called upon to interpret, reconstitutes the speech from those notes. It is my contention that this schematic notation of the semantic features of the discourse results from the application of the macrorules to the micropropositions of the original message, and that the interpreter's notes reproduce the resultant macropropositions. When the interpreter reconstitutes the message in the TL, she or he has again applied the macrorules, this time in the inverse direction, in order to derive the micropropositions. In simultaneous interpretation, memory is involved in a less systematic manner although the process of memory search necessary to identify argument overlap and co-reference for the purpose of comprehension are as essential as in consecutive interpretation. In simultaneous the interpreter will be engaged in processing (phonologically and semantically) incoming segments of discourse at the same time as producing in the TL, the segment that has already completed that process (i.e. checked for relevance and coherence, and stored in short-term memory for matching with subsequent incoming segments). A segment will vary in the number of micropropositions it contains according to the processing strategy of the interpreter, the macrostructures of the discourse, etc. If this description is correct, it suggests that the processing load of an interpreter working in simultaneous is greater than that of an interpreter working in consecutive who has fewer operations to execute simultaneously. While the process of note-taking and message-analysis in consecutive can be described in terms of macrostructures, the recourse made to macrostructural processing in simultaneous is not directly observable, although examples of errors (discussed later) indicate that message loss may be due to the inability in a particular instance to relate a microproposition to the macrostructure, or to the formation of incompatible propositions. Evidence about the formation of macrostructures and macropropositions could be obtained by asking a set of interpreters to undergo a recall test after interpreting. If the interpretation protocol is scored and if those scores were to correlate with the scores on the recall test, message integrity in simultaneous interpretation could be seen as a function of macrostructural processing. The schemata within which the interpreter construes meaning play an important part in organising the application of the macrorules and restricting the lexicosemantic choices the interpreter has to make. 


\section{EXPERIMENTAL RESULTS}

In an attempt to verify the applicability of the Kintsch and Van Dijk model to CI, an analysis was made of protocols from a consecutive relay experiment (1982) and a similar simultaneous experiment (1983). The consecutive study involved an experimental group and a control group of eight student interpreters each, at the end of a sixmonth course in CI techniques at the Polytechnic of Central London. The experimental group interpreted in consecutive from English to Italian to English to Spanish to English to French to English to Arabic to English. The control group relayed the message from English to English, eight times. All subjects interpreted into their A language with the exception of No 8 in each group who worked into the B language. The subjects for the simultaneous experiment were 10 professional conference interpreters ( 8 AIIC members, 2 candidates), divided into five pairs of one English $A$ and one French $A$ per pair. Two speeches were delivered, the one in English was interpreted into French and relayed back into English by the two members of each pair. The second speech was in French and the opposite procedure obtained (for full account see J. Mackintosh : AILA 84). Both speeches were on the EEC fisheries policy. The results discussed below are taken from No 2 in each of the two consecutive streams and from one of the direct French to English protocols of the simultaneous experiment.

The most common feature to emerge from these studies was that under some conditions the standard of $L_{1}$ suffers. If we assume that the extent to which the level of $L_{1}$ departs from the standard level is an indication of the demands the task puts upon the interpreter (comprehender-producer), it would appear that self-cued recall from $L_{1}$ into $\mathrm{L}_{1}$ at the interpreter's own pace (i.e. consecutive from English into English in the above example) is the least demanding of the three conditions. Errors such as respectable instead of respected are immediately self-corrected (the original term used was eminent). When the interpreter is operating in two languages, there are many more departures from standard English : in the consecutive condition these take the form of awkwardness of formulation whereas in simultaneous, not only are some of the expressions clumsy but there are grammatical errors, e.g. certain licences imposed that the beneficiary has the obligation of landing their catches. Definite articles appear in the position they occupy in French, e.g. the processing in Guyana, and verb and pronominals do not match. The protocols indicate that simultaneous interpretation is the task imposing the heaviest processing load, on the basis of departures from standard English, and this observation concurs with the conclusion drawn by Lambert (1983) on the basis of her data. Similarly, in both sets of data, consecutive reiteration without language-switching emerges as the least demanding task, on the basis of recall scores in Lambert and on the basis of departure-from-standard in the above example.

The deletions that occur, such as two red flares rose as a signal to fire the rocket* becoming while the signal to fire was being given suggests macrostructural rearrangement, especially given the addition of the connective while. Similarly the fact that the $V 2$ rocket of the original becomes a streak in the interpreted version can be seen as an extreme case of generalisation. In the simultaneous experiment which, as seen above, showed the highest level of linguistic decay, most of the micropropositions of the original are present in the TL text. An indication that interpreters working in simultaneous also process the message in the manner described by the model is to be found in soit plus de 13 milliards de centimes being rendered (incorrectly) by which is about 13 times more than they are getting at the moment. Here the interpreter has to process an unfamiliar concept (to her listeners if not to her) for which a meaningful equivalent has to be found. The TL version suggests that in searching for argument overlap, under a severe time constraint, coherence was deemed to be of overriding importance and the state- 
ment made by the interpreter is coherent with the overall schema of the text and its macrostructures. Van Dijk (1980) refers to the role of cognitive sets in the comprehension process, he defines a cognitive set as

The set of factors that in a particular context of action or discourse processing influences macrostructures is called the cognitive set of a language user or participant. (Van Dijk $1980: 201)$

and in the example quoted above we see how the need to operate three cognitive sets simultaneously (the one the interpreter assumes for the speaker; the interpreter's own cognitive set which must not be allowed to intrude if possible ; a hypothetical cognitive set for shared by the interpreter's listeners) can, when any of these are obviously at variance, increase the processing load to the point that part of the message is forfeited. The example quoted also suggests that decisions about what is not to be forfeited are informed by the macrostructures of the text.

\section{DOES THE MODEL FIT ?}

It appears to fit the processes involved in consecutive interpretation and to provide us with a more discrete view of the various stages. As consecutive interpretation is more easily observable (e.g. an analysis of interpreters' notes) than simultaneous, our inability to be as affirmative about the latter is a measure of that difficulty rather than of any inadaptation of the model. The model offers us a theoretical description of the processes of comprehension and production and possible explanations for errors and omissions. Models of short-term and long-term memory are likely to contribute to our understanding of these ; the particular value of this model is that it provides a set of mapping rules which link the stages in the process and explain why certain things occur. For example, the failure to delete information that is irrelevant to the next macrostructural level will produce a distortion in emphasis; a failure to generalise will disrupt the processes of cohesion; a failure to construct will obscure topic gist. The areas that it does not elucidate at all include problems relating to simultaneous interpretation, such as what level of macrostructural processing is necessary for surface text comprehension without the recall task because we cannot measure how much of the processing is effected in response to the comprehension and how much in response to the recall task. Similarly, very little evidence is available with regard to the additional load constituted by the two-language condition although experimental results from the consecutive relay experiment suggest that it increases it. Kintsch (1974) produces experimental evidence to suggest that inferencing if effected during reading and not during recall - experimental evidence is now needed to indicate how much other processing is effected during reception-comprehension and, in particular, how we can measure the load constituted by the language switching task in relation to those of the other tasks performed by an interpreter in consecutive and simultaneous.

I hope that this brief discussion has illustrated how text linguistics, psycholinguistics and work undertaken by interpreters are moving towards the outlining of a broad model that in turn may serve to build up the as yet rather flimsy theoretical base on which our understanding of consecutive and simultaneous interpreting rests.

* The text used for the consecutive relay experiment was taken from de Beaugrande and Dressler (1981):p. 1.

REFERENCES

DE BEAUGRANDE, R. \& W. DRESSLER (1981) : Introduction to textlinguistics, London, Longman. GERVER, D. (1976) : "Empirical Studies of Simultaneous Interpretation : A Review and a Model", in R. Bresling (ed.), Translation : Applications and Research, New York, Gardner Press.

HERBERT, J. (1952) : Manuel de l'interprète, Genève, Georg. 
ILG, G. (1980) : "L'interprétation consécutive", in Parallèles, no 3, Cahiers de l'École de traduction et d'interprétation, Université de Genève.

KINTSCH, W. (1974) : The Representation of Meaning in Memory, Hilisdale, N.J., Erlbaum Associates. KINTSCH, W. \& T. VAN DIJK (1978) : "Toward a Model of Text Comprehension and Production", in Psychological Review, 85, pp. 363-394.

LAMBERT, S. (1983) : Recognition and Recall among Conference Interpreters, Ph.D. thesis, University of Stirling, unpublished.

LEDERER, M. (1976): "Synecdoque et traduction", in Études de linguistique appliquée, no 24, Paris, Didier. LEDERER, M. (1981) : la Traduction simultanée - Expérience et théorie, thèse d'État, Paris, Minard lettres modernes.

MOSER, B. (1978) : "Simultaneous Interpretation : A Hypothetical Model and its Practical Application", in Gerver \& Sinaiko (eds.), Language Interpretation and Communication, New York \& London, Plenum Press.

ROZAN, J. (1956) : la Prise de notes en interprétation consécutive, Genève, Georg.

SELESKOVITCH, D. (1977) : "Why Interpreting is not Tantamount to Translating Languages", in The Incorporated Linguist, vol. 16/2, London.

SELESKOVITCH, D. (1975): Langage, langues et mémoire, Étude de prise de notes en interprétation consécutive, Paris, Minard, Cahiers Champollion, Lettres modernes.

VAN DIJK, T. (1980) : Macrostructures - An Interdisciplinary Study of Global Structures in Discourse Interaction and Cognition, Hillsdale, N.J., Erlbaum Associates.

WILLETT, R. (1974) : "Die Ausbildung zum Konferenzdolmetscher", in V. Kapp (ed.), Uebersetzer und Dolmetscher, Heidelberg, UTB Quelle \& Meyer. 